\title{
Alterior reflections from Asian philosophies: Levinas and the comparative way
}

\author{
David Jones ${ }^{1}$
}

Received: 7 June 2015/Revised: 19 June 2015/ Accepted: 20 June 2015/Published online: 9 July 2015 (C) Academy for International Communication of Chinese Culture and Springer-Verlag Berlin Heidelberg 2015

\begin{abstract}
Following the lead by Levinas, this paper suggests that the Western philosophical vision is in need to see itself vis à vis other visions of humanity that recognize different places for humans in the natural world, social world, and in the heavens. Moreover, an exclusive Western vision needs alterity to see itself for what it more truly is. Casting our gaze toward the Asian philosophical traditions, especially the Chinese and Indian traditions, provides the West with this needed reflection. By lifting ideas from the Asian philosophical tradition vis à vis the Western, the West can gain a greater understanding of itself by looking at the other.
\end{abstract}

Keywords Alterity - Levinas · Responsibility - The Other · Face-to-face · Comparative philosophy $\cdot$ Guñas $\cdot$ Dasein $\cdot$ Confucius $\cdot$ Dao $\cdot$ Bhagavad-Gita

The Western philosophical vision is in need to see itself vis à vis other visions of humanity that recognize different places for humans in the natural world, social world, and in the heavens. An exclusive Western vision needs some alterity to see itself for what it more truly is. Casting our gaze toward the Asian philosophical traditions gives us this alterior reflection. The philosophical traditions of Asia, especially China and India, have long developed histories of intellectual engagement. Asian philosophies, like their Western counterparts, have developed rules and conventions governing truth claims, theories about the meaning of words, the basis of morality and justice, the nature of death, and the meaning of life. By lifting ideas from the Asian philosophical tradition vis à vis our own, we can gain a greater understanding of ourselves by looking at this Other.

David Jones

djones@ksuweb.kennesaw.edu

1 Kennesaw State University, Kennesaw, GA, USA 
What does the encounter with the Other ultimately mean to Western philosophy? Let me suggest this encounter with the Other is the encounter with our authentic and ethical selves, because this encounter with the Other breaks through the dialogue of the silence of our solipsistic being and shows us our own face; the encounter with the Other reveals our true face, reveals this face of ours initially in its face, the face of the Other. The face of the Other is the elementum, the archē, the first principle that is the ground of interpersonal contact and the ground for which nonhuman contact is made possible. This ground of the Other indicates an immediacy with other persons and other species that Levinas calls "proximity." Levinas writes that "the proximity of the Other is not simply close to me in space, or close like a parent, but he approaches me essentially insofar as I feel myself-insofar as I amresponsible for him" (1985, p. 9). For Levinas, proximity is felt as immediate contact because proximity demands a response from us-a responsibility- the possibility, and ability, to respond. This proximity is a weight that comes from the outside; the self as subject is subjected to the Other; the Other who comes upon us to engage us in self-conversation, a conversation that interrupts the solipsistic silences of our ego-sophic dialogues that we now can come to know through this encounter as monologues. We have become comfortable calling this monologue our lives, "my" life, whose accustomed silent utterances comfort us, comfort me.

Without this encounter, I am not a person. As Martin Buber suggests in I and Thou, "Egos appear by setting themselves apart from other egos. Persons appear by entering into relation to other persons" (111). We see something quite similar in the Chinese ideal of ren 仁, or consummate conduct, that guided Herbert Fingarette to say, "For Confucius, unless there are at least two human beings, there are no human beings" (217). When Socrates challenges us to know ourselves, he does so in the spirit that we need to get beyond the ego that desires to tyrannize the rest of the soul and becomes the heroic ego that James Hillman and Bruno Bettelheim caution against in our misreading of Freud. But we cannot seem to get beyond Hillman and Bettelheim's sound advice because the popular wisdom is that Freud was wrong, and we often get this from the very science that Freud himself respected. This "I" of Socrates and his therapeutic prescriptions for the soul became Spirit for Christian theologians and once their theologies are in place, there would never be a way back to Socrates' insight - that introspection discloses a person's true arēte, that is, her true ability of excellence and being as a soul that directs the body in its intellectual and moral agency. Although different in their cultural contexts, Aristotle's inherited sense of arēte from Homer onwards can be revived by turning toward the de 德 of Confucianism. The "courtly morality" of arête, which accompanied pride and valor in Homer's Greek, ${ }^{1}$ is long forgotten in the tradition without having Confucian philosophy in mind, that is, to remind us that the Greeks too valued $l i$ as an integral part of what it meant to be an aristos, to be a noble person and failure to do so was to become hubristic, the worst of all Greek transgressions. As Werner Jaeger has stated in his classic, Paidea: The Ideals of Greek Culture,

\footnotetext{
${ }^{1}$ From Jaeger, 5.
} 
... the higher social standards of the polis were derived from aristocratic practice.... In Homer, the real mark of a nobleman is his sense of duty. He is judged, and is proud to be judged, by a severe standard. And the nobleman educates others by presenting to them an eternal ideal, to which they have a duty to conform. His sense of duty is aidos. Anyone is free to appeal to aidos; and if it is slighted the slight awakens in others the kindred emotion of nemesis. (7)

To present a standard to others is to live a role as Henry Rosemont has repeatedly reminded us, especially in his new book Against Individualism, and without the lens of Confucianism, it becomes increasingly difficult to see this aspect in the roots of Western philosophy. The Greeks too were role-bearers who were "proper models for others to emulate." 2 The point here is not to draw direct parallels or a one-to-one correspondence between the ancient Greeks and Chinese, but is rather to suggest that being so entrenched and defined by a cultural and historical context of received tradition often blinds us to some essential qualities that formed our very worldview. The dialectical otherness of another culture can show us expressions of our own faces that have been removed by time and various philosophical and theological agendas.

That we are always and ultimately responsible for all that we are and do, including our karmic facticity, is forever obstructed from our sight. How does one arrive at the Socrates, for example, who envisions love's body in its five-stage ascent to the Idea of Beauty/Good as a necessary condition for the self-emergence of its universal particularity? The conflated soul/spirit of those later, and lesser, Socratics shields the philosophical inquirer from Socrates' existential affirmation of the erotic body in its quest of the beautiful and the good, of the aesthetic and ethical life-world. How can we make audible the groans, grunts, exhalations of the life's breath of this erotic quest when soul is made spirit and agápe dominates and subjugates the eros of body? How can we begin to hear Socrates without the Bhagavad-Gita?

The Bhagavad-Gita gives us the needed alterity to see the importance of the erotic body in the soul's ascent to the Intelligible in the Symposium. When we engage the text of the Symposium without the revenues salaried to us from the investments of our tradition, we can discover that the insight of Indian philosophers can be transferred and allocated directly to our understanding. In other words, we must not read the Symposium to read the Symposium, but we must read the Bhagavad-Gita to read the Symposium. The Mahäbhärata assumes the doctrine of the three constituents of prakrsti. The three guñas of sattva, rajas, and tamas are present in various degrees in all things and fetter the soul from its higher release; and we can see this easily in Bhagavad-Gita without the interruption of our tradition. Their interaction condition character and must be taken seriously because they yield classes, which resemble the three classes we see in Plato's perfect society, and because they represent the necessary forms of yoga needed to bring their energies of intelligence, passion, and materiality under control. The Bhagavad-Gita encourages us to see the relevance of the body and its eros without any post-Platonic baggage and the requisite control needed to be

\footnotetext{
${ }^{2}$ From Henry Rosemont Jr.'s "We All Think We're Individuals. Here's Why That's Not True, and Why the Lie is Told" in Huff Post Politics, 25 May 2015. http://www.huffingtonpost.com/henry-rosemont-jr/ post_9486_b_7424312.html.
} 
exercised upon the thumos (spirited and feeling) and epithumos (appetitive) soul by the logistikón, the highest part of the soul for Plato. Perhaps we can see for ourselves the proper regulation of eros and the Symposium's affirmation of learning to cooperate with the desires of erotic bodily love without aid from the Bhagavad-Gita. But when we see its alterior reflection from the perspective of our reminiscence of reading the Symposium, we reflect back to the absent text as it presences itself and realize our heretofore glossed reading. Returning to the Symposium through the lens of the Bhagavad-Gita discloses a deeper and more authentic reading that was overlooked by years of the obscured vision of bodiless transcendent immortal souls practicing only agapic love at the expense of the erotic, which was something Plato seemingly never intended, nor would have understood. Plato, much like the Bhagavad-Gita thinkers, understood the necessity of cooperating with the body and its multi-layered levels of eroticism if transcendence was ever to be achieved. The facticity of the life-world of the body in Platonic philosophy is given presence by reading the Bhagavad-Gita without impairing its beauty or injuring its truth.

Facing this Other as a reflection of our existential alterity is a joyous event for those who are brave enough to give up their heroic and transcendental egos-those brave souls who want their solipsistic monologues interrupted. What is suggested here is that we all ultimately desire the interruption of this solipsistic monologue, for we are tired of ourselves being just our-selves. We want the Other so we can have conversation, dialogue - a going through language - to discover ourselves. Often, we initially appropriate the Other of Asia as the self of ourselves in a spiritual way; an appropriation laced with the rubric of spiritual affectation. We have come home, we have arrived at the doorstep of the Other, or so we wishfully think. But all we have done is suppressed the Other, brought it into our possession, and we have made it the same.

This type of appropriation we experience, try out, put on trial, just doesn't seem to fit, just doesn't seem to get us very far except in deceiving ourselves. And as Sartre warns us, this is the worst of all kinds of deceptions; it is to live in bad faith. What I am suggesting here is that we need to go beyond this test, this trial, and to go beyond this experience. The proximity of the Other demands a more authentic response; the response with the Other demands that we become responsible. In the spirit contra Sartre who proclaims that "Hell is other people" (L'enfer, c'est les autres) in his No Exit, Levinas finds the possibility of responsibility, even the possibility of ethics, in the moment of the encounter with the Other. For Levinas, we must allow the Other to enter our horizon.

A calling into question of the same-which cannot occur within the egoist spontaneity of the same-is brought about by the other. We name this calling into question of my spontaneity by the presence of the Other ethics. The strangeness of the Other, his irreducibility to the I, to my thoughts and my possessions, is precisely accomplished as a calling into question of my spontaneity, as ethics. Metaphysics, transcendence, the welcoming of the other by the same, of the Other by me, is concretely produced as the calling into question of the same by the other, that is, as the ethics that accomplishes the critical essence of knowledge. And as critique precedes dogmatism, metaphysics precedes ontology. $(1969,43)$ 
The self takes on a new direction and dimension in this encounter; this new dimension is a new subjectivity; the encounter is the self discovering itself to be a self: a Westerner who is not pretending to be non-Western, but a Westerner who begins to discover her own tradition and then realizes the meaning of what Confucius says when he proclaims of the consummate person, "in wanting to establish himself, he establishes others; in wanting to succeed himself, he helps others to succeed" (Analects 6:30).

When we encounter the Other, we find a new subjectivity. This newly discovered subjectivity can also presence itself in the work of the Western philosopher. A more interesting Herakleitos and Empedokles can be found if we encounter Laozi and Zhuangzi; finding a more robust and thought provoking Plato and Aristotle can come through an encounter with Shankara and Confucius. The possibility of recognizing, and then re-cognizing, ourselves and our own tradition, is provoked and enhanced when the Other comes into view. The fascinating Herakleitos and Empedokles are not the ones read backwards from Platonic Idealism or idealism adapted by Aristotle. By engaging these Greek thinkers through the otherness, the absolute alterity, of Daoist thought allows the possible space-creates the possibility of this space to philosophize authentically-to engage them more directly without the impoverishment of their subsequent history. As if fifth century Athenian philosophy had anything whatsoever to do with the sixth century Ionian or Sicilian thinking about the nature of things!

The Herakleitos we come to without the interpretive lens of Daoism is that "practically all aspects of the world are explained systematically, in relation to a central discovery - that natural changes of all kinds are regular and balanced, and that the cause of this balance is fire, the common constituent of things that was also termed their Logos" (Kirk and Raven 214). Fine enough, but if we read Chinese philosophy and then return again to Herakleitos, we uncover a new thinker, not one deprived by his subsequent tradition. We discover a more vibrant Herakleitos whose fire is not literalized as some archē and that this element is somehow mysteriously construed as the Logos, the systematic principle that explains all things and their relations with each other. Herakleitos' logos is simply not Plato's Idea of the Good.

In the Daodejing and the Yuan Dao, fire's opposite, its opposing force, its absolute alterior element that even renders its death, is used to give presence to dao because the way water functions, the way it acts in the world is similar to dao. But water, as is Herakleitos' fire, is only one of the fundamental wuxing (processes, phases, or more metaphysically translated as elements) ${ }^{3}$ of the Chinese worldwater, earth, fire, metal, and wood (metal and wood are not part of the elementum natura of the Greek world). Hence, water cannot be considered as the world, as a first cause, or as a causal principle because this particular wuxing only represents $d a o$, the sum of all the world's orders. Herakleitos' fire is not the world's Logos as many have suggested - as if he was unaware of or considered the other elements nonessential in forming the various overlapping orders of the process we call world.

\footnotetext{
3 I follow A. C. Graham's translation of wu hsing as processes, which "were generally known in English as the Five Elements." See A. C. Graham, Disputers of the Tao [DT] (La Salle, Illinois: Open Court Press, 1989) 356.
} 
In the Daoist tradition, water was allowed to be the soulful personifying of $d a o$, and dao is manifested as water because classical Chinese cosmology does not necessitate a transcendently single-ordered cosmos, but "invokes an understanding of a dynamic 'world' that is the sum of daos construed by a myriad of unique particulars - 'the ten thousand things'" (Lau and Ames 16). The Ionian worldview, long before Plato's teachers and students, had this same kind of dynamic worldview with overlapping, coextensive, and emergent logoi, that is, proportionate orders exhibiting self-similarity across scale. But we cannot help ourselves from reading backwards, from reading Herakleitos through Plato's texts and those subsequent texts of Western philosophy's grand narrative. Even Gadamer, one of the greatest hermeneutic thinkers, read the ancients this way. How do we prevent ourselves from this backward reading?

If we asked, as Lau and Ames have, whether "water is one or many? Does water have a formal coherence that is persistent? Can water be meaningfully separated into 'things,' and if so, do such things persist? Is water noble, or is it base? Is it a thing ('water') or an action ('to water') or an attribute ('watery') or a modality ('fluidity')?" can we not ask the same of Herakleitos' fire? And must we not conclude that both fire and water are all of these? Hence the imagery of fire and water-their various expressions through a variety of images-when placed in language becomes a figure of speech where a more inclusive term is used for less inclusive ones such as $q i$ or logos and avoids the reified term "world." All of Herakleitos' nuances of fire when turned back on themselves from their alterity of water offer a reflection of the vital material force of logos through understanding it as $q i$, as "the vital sea of energy that is both constitutive of the world and an expression of its activities" (Lau and Ames 17).

As suggested by its Greek roots, the English word "metaphor" suggests that meaning is more meaningfully carried across and through the use of metaphor. These elemental images remind us of the source for all that is animated-that has soul - in the world; water reminds us of this source more than vital material energy that is defined by the word "qi." Cannot fire do the same for logos? Fire reminds us of the destructive force, which is more profoundly seen as the necessary condition and outcome of all creation-fire destroys, but rejuvenates through its destruction. Its flames dance much like the dancing Shiva who is himself contained within the immanence of a fiery ring and who dances this world as a possible world into being, and maintains its being through his dance, and dances it out of being while squashing the breath from ignorance's natal form. The demon of ignorance strikes a victory if we conclude with Hegel in his characterization of "Oriental Philosophy" that "the first Philosophy in order is the so-called Oriental, which, however, does not enter into substance or range of our subject [because] its position is preliminary, and we only deal with it at all in order to account for not treating of it at greater length, and to show in what relation it stands to Thought and to true Philosophy" (117), that is, to European thought. Although Herakleitos is given a "good" read by Hegel, poor Empedokles is left to just one near page shared with Leucippus and Demokritos. Perhaps the "so-called Oriental philosophy" has much more to offer us than what Hegel neglected to think, to think even more deeply in a measured way about his own tradition. 
The image of water allows us to see dao as meandering, surging, gushing and rushing, and moving forth without design or intended purpose; the image of water prompts us to see its other side of being weak and submissive such as when in a cup; the image of water allows us to see its transformation into ice and steam. Dao moves like water uninterrupted in patterns of circularity (fan), or always as a "turning back" of dao that means two things: the flow or interplay between the opposites of yin and yang, and a re-turning of the myriad things back to their source, that is, being resolved back into other things (Lau and Ames, 25). On the level of phenomenal particulars, each of the "myriad things" is a combination of yin and yang forces. When a particular phenomenon increases and reaches its terminus, it must necessarily change directions and recede toward its other side; it ebbs and tides as it moves through its own cycles conditioned by other cycles. Is this not Herakleitos' logos too where "one cannot step twice into the same river; nor can one grasp any mortal being a second time in succession, but swift and piercing it changes scattering and it gathers again, again and later, but at once it forms and dissolves, and approaches and lets go" (Fragment 12)? Is this not his Shiva, "the god [who] is day/night, winter-time/summer-time, war/peace, satiety/hunger, all the opposites, this is the sense; and he is changed just as fire, which when it [the god] is blended with that which is burnt, it [the god] is named according to the pleasures of each" (Fragment 67)? Thus, when the god is blended with a material that is burnt, it is named according to its transfigured form and this form is not something substantial, but is a scent. The blending of the successive opposites in this fragment is the circularity of fan. How do we understand this eternal cycling where all particular phenomena are engaged in and emerge from the immanent patterning of the world where a unity is revealed in their multiplicity? Does not Daoism help us to see this? These immanent patternings and their tendency for emergence are logos and dao as expressed as the sum of the orders, which is a consequence of the particulars comprising the totality of existing things (Hall and Ames 245). The Yuan Dao pushes the water analogy even further than the Daodejing. Water is at once yinyang because:

In the world there is nothing more pliant and weak than water

And yet it is great beyond reckoning

And deep beyond fathoming,

In length it ends only in the interminable

And in distance it merges into the boundless;

Waxing and waning, increasing and decreasing,

It runs into the incalculable,

Going up to the heavens it becomes rain and dew;

Going down to the earth it becomes moisture.

The myriad things cannot produce without it,

And the events of the world cannot culminate without it

(Lau and Ames 103)

Water "mixes" and "coalesces" but "cannot be divided" (103). Its undivided state gives rise to all particular differentiated things comprising the totality of existing things and their immanent patterning. And Herakleitos has it in much the same way: 
"This kosmos is the same for everything, not any of the gods, nor men has made, but it always was and is and will be; an ever-living fire, kindling itself in metres and quenching itself in metres." Daoism helps us see the absence of some ghostly hand, some unknown postulate or mysterious metaphysical being, in Herakleitos' thought that steers the events of the world along their course. In their stead, Herakleitos gives us a fiery lightning bolt called prēstèr. His choice of this word instead of keraunos, which refers exclusively to fire, is crucial because prēstēr can also mean a forceful rainstorm such as a hurricane. Herakleitos' archē fire contains in itself its alterior reflection. The Daoist lens allows us to see this focus of his thought while Greek scholars miss his "stronger unseen harmony" (Fragment 53).

We cannot help but read those of our tradition through the eyes of that very tradition itself; we are forever lost in the spiraling play and unconscious participation in the tradition from which we emerge. As Nietzsche warns in Beyond Good and Evil (\$264), "one cannot erase from the soul of a human being what his ancestors most liked to do." What our Greek, German, French, Danish, and British ancestors most liked to do was think about the meaning of words, the basis of morality and justice, the nature of death, and the meaning of life. The very things we still think about from the grounding of our inherited tradition. We think Being, and the being of self, the same.

For those of us who wish to extend the conversation to include the others of the Other, to move ourselves to the social, aesthetic, metaphysical, and epistemological levels more specifically, we can begin to ponder: when we study other cultures, when we attempt to understand the Otherness of others and their culture and the Other's view of self and world, the question of "understanding" itself arises. Whose understanding, whose categories of understanding, or whose categories of knowing, are we employing when we try to understand another's culture and the worldview it constructs? Once we are at this place, this place of being able to ask this question, we are ready for the first time to reflect meaningfully on our own cultural assumptions and predilections. Kant would have these categories as universal, but as Stephen Goldberg has enjoined us that "to reflect on our own cultural assumptions [is] a way of opening up a space within which to consider a very different set of assumptions in-forming another's culture." To reflect in this way is to avoid what Goldberg has referred to as the "hardening of the categories." These hardened categories occlude the flow of inquiry that meaningfully reflects on what is real, what is good, and how we can come to know. And ultimately, this occluded inquiry impoverishes the flowing subjectivity of the life-world of the inquirer and betrays those life-worlds of other sentient beings we encounter.

In the face of the Other, we see the original face of our own assumptions and our own tendencies of trying out our reality, as is suggested by the Latin roots of the word experience (ex + per, in Latin experientia is a test, a trying out of reality). Our experience in the world is a trying out, a testing, of our understanding that is knotted by the very experience of knowing itself. When we encounter this face of the Other, we open a space within, and see ourselves. And as Stephen Goldberg adds, "The rest is commentary." 4

${ }^{4}$ Unpublished quotes by Stephen J. Goldberg. 
Levinas is instructive for our purposes in comparative philosophy. His farreaching idea that Western philosophy has been a repression of the Other and this Other is in need of protection from the aggressions of the same, of this self, this selfsame-self introduced into our discourse by Plato, is not news to us. But Levinas through his close readings of Husserl and Heidegger realizes their failures in maintaining a responsible and rewarding encounter with the Other, because every encounter with the Other always entails a return for them to the self as a "solitary ego which has no relationship with the other qua other, for whom the other is another one, an alter ego known by empathy, that is, by a return to oneself" (Existence and Existents, 85). In his earlier work, Levinas largely ignores the issue of solipsism in Husserl, but his later philosophy is at odds with this possible conclusion of Husserl's project, which even Husserl himself was aware of in his fifth "Cartesian Meditation." Levinas also wishes to move beyond Heidegger because he correctly sees Heidegger as more concerned with modes of Being rather than the encounter between beings. Even though Heidegger clearly avoids the solipsistic tendencies in Husserl with his Mitsein (Being-with) and Mitwelt (withworld) where Dasein always shares a world with others, Levinas realizes this Dasein is a solitary being that does not necessarily promote any real encounter with the Other. Although there is no transcendental ego for Heidegger seeking a vicarious "empathy" with other transcendental egos through the bodies and behavior of others, Heidegger still falls into some metaphysical trap of the same (self) for Levinas. As Heidegger writes, "Dasein as Being-with lets the Dasein of Others be encountered in its world. Being-with is in every case a characteristic of one's own Dasein; Dasein-with characterizes the Dasein of Others to the extent that it is freed by its world for a Being-with. Only so far as one's own Dasein has the essential structure of Being-with, is it Dasein-with as encounterable for Others" (157). Both Husserl's empathy and Heidegger's Being-with fail for Levinas.

Our encounter with the Other needs to be more authentic, more responsive, and more intimate. The Other must remain in its otherness, that is, maintain its integrity and dignity as Other. I have been suggesting that our response to the Other is most meaningful in understanding our own texts and tradition when we are not being just empathetic and solitary (as Levinas sees Husserl) and concerned with Being at the expense of beings (as Levinas sees Heidegger) in this encounter. Our encounter, however, as does Levinas', needs to avoid the intimacy of Being as found in Heidegger because the Other is constituted by its absolute alterity and is ultimately unknowable. We cannot possess it, own it, or even appropriate it; we must continually face our shortcomings in being able to treat it with dignity, respect, and goodness. The Asian traditions are not to be suppressed, possessed, or appropriated. They remain in their Otherness to Western philosophers. As Levinas says in Time and the Other, "the relationship with the other is a relationship with a Mystery" (75). This mystery must be preserved in our encounters even if there is utility in our approaching these Others. If we are incapable of this approach, we fall victim to our own ills in the West: "Western philosophy coincides with the unveiling of the other in which the Other, by manifesting itself as a being, loses its alterity. Philosophy is afflicted, from its childhood, with an insurmountable allergy: a horror of the Other which remains Other. It is for this reason that Philosophy is essentially the 
philosophy of Being; the comprehension is its final word and the fundamental structure of man" (En décourvrant l'existence avec Husserl et Heidegger 188). In seeking the ground of Being, Western philosophy has left the Other ground-less. To restore this ground to the Other is Levinas' project of the ethical.

The task for comparative philosophers is to develop ways that preserve the independence of Asian traditions without bringing them into the sphere of the familiar. To accomplish this task, we must not allow the Asian philosophical traditions to be the objects of our knowing or experiencing because their alterity will be lost to our knowing, our experiencing, and this encounter will be for us and our world.

I am responsible for the Other without waiting for reciprocity, were I to die for

it. Reciprocity is his affair. It is precisely insofar as the relation between the Other and me is not reciprocal that I am subjection to the Other; and I am "subject" essentially in this sense. It is I who support all... The I always has one responsibility more than all the others. (Levinas 1985, 98)

We may wish to eradicate this Other as Hegel attempts to eliminate the "so-called Oriental" in his History of Philosophy, but as Hegel could not, we cannot. The Other remains resolute. My face-to-face relation with this Other, with the Asian philosophical traditions, does not afford me contentment or intimacy or anything like that. My face-to-face relation discloses a world outside of myself, outside of my tradition, a world of innumerable others and fills me with an absolute obligation to and a responsibility for this Other. And I will never be able to fulfill this obligation and responsibility in my role as a comparative philosopher, or as a human-being, even in my post-solipsistic being in the shadow of the Other, for it remains an ongoing encounter.

\section{References}

Ames, R. T., \& Rosemont, H., Jr. (1998). The analects of Confucius: A philosophical translation. New York: Ballantine Books.

Fingarette, H. (1983). The music of humanity in the conversations of Confucius. Journal of Chinese Philosophy, 10, 129-140.

Hall, D. L., \& Ames, T. R. (1998). Thinking from the Han. Albany, NY: State University Press.

Hegel. (1802). Lectures on the history of philosophy (Vol. 1, E. S. Haldane, Trans.). London: Kegan, Paul, Trench, Trübner and Company.

Heidegger, M. (1962). Being and time. (J. Macquarrie \& E. Robinson, Trans.). New York: Harper and Row.

Jaeger, W. (1939). Paidea: The ideals of Greek culture (Vol. 1, G. Highet, Trans. 1939, 1945, Oxford University Press, 1965). New York: Galaxy.

Kirk, G. S., \& Raven, J. E. (1957). The presocratic philosophers: A critical history with a selection of texts. Cambridge, MA: Cambridge University Press.

Lau, D. C., \& Ames, R. T. (1998). Yuan Dao: Tracing Dao to its source. New York: Ballantine Books.

Levinas, E. (1969). Totality and infinity: An essay on exteriority (A. Lingis, Trans.). Pittsburgh: Duquesne University Press.

Levinas, E. (1985). Ethics and infinity: Conversations with Phillipe Nemo (R. Cohen, Trans.). Pittsburgh: Duquesne University Press. 
Nietzsche, F. (1966). Beyond good and evil (W. Kaufmann, Trans.). New York: Vintage Books.

Nietzsche, F. (1967). En décourvrant l'existence avec Husserl et Heidegger. Paris: Vrin.

Nietzsche, F. (1987). Time and the other. (R. A. Cohen, Trans.). Pittsburgh: Duquesne University Press.

Rosemont, H., Jr. (2015). Against individualism: A Confucian rethinking of the foundations of morality, politics, family, and religion. Lanham, MD: Lexington Books. 